\title{
A Decomposition of the Atlantic Meridional Overturning Circulation into Physical Components Using Its Sensitivity to Vertical Diffusivity
}

\author{
Juliette Mignot,* Anders Levermann, And Alexa Griesel ${ }^{+}$ \\ Potsdam Institute for Climate Impact Research, Potsdam, Germany
}

(Manuscript received 19 November 2004, in final form 26 September 2005)

\begin{abstract}
The sensitivity of the Atlantic Ocean meridional overturning circulation to the vertical diffusion coefficient $\kappa$ in the global coupled atmosphere-ocean-sea ice model CLIMBER-3 $\alpha$ is investigated. An important feature of the three-dimensional ocean model is its low-diffusive tracer advection scheme. The strength $M_{\max }$ of the Atlantic overturning is decomposed into three components: 1) the flow $M_{S}$ exported southward at $\left.30^{\circ} \mathrm{S}, 2\right)$ the large-scale upward flow that balances vertical diffusion in the Atlantic, and 3) a winddependent upwelling flux $W_{\text {bound }}$ along the Atlantic boundaries that is not due to vertical diffusion. The export of water at $30^{\circ} \mathrm{S}$ varies only weakly with $\kappa$, but is strongly correlated with the strength of the overflow over the Greenland-Scotland ridge. The location of deep convection is found to be mixing dependent such that a shift from the Nordic seas to the Irminger Sea is detected for high values of $\kappa$. The ratio $R=M_{S} / M_{\max }$ gives a measure of the interhemispheric overturning efficiency and is found to decrease linearly with $\kappa$. The diffusion-induced upwelling in the Atlantic is mostly due to the uniform background value of $\kappa$ while parameterization of enhanced mixing over rough topography and in stratified areas gives only a weak contribution to the overturning strength. It increases linearly with $\kappa$. This is consistent with the classic $2 / 3$ scaling law only when taking the linear variation of the density difference to $\kappa$ into account. The value of $W_{\text {bound }}$ is roughly constant with $\kappa$ but depends linearly on the wind stress strength in the North Atlantic. The pycnocline depth is not sensitive to changes in $\kappa$ in the model used herein, and the results suggest that it is primarily set by the forcing of the Southern Ocean winds. The scaling of the total overturning strength with $\kappa$ depends on the combined sensitivity of each of the terms to $\kappa$. In the range of background diffusivity values in which no switch in deep convection sites is detected, $M_{\max }$ scales linearly with the vertical diffusivity. It is argued that scalings have, in general, to be interpreted with care because of the generally very small range of $\kappa$ but also because of possible shifts in important physical processes such as deep convection location.
\end{abstract}

\section{Introduction}

The northward heat transport in the Atlantic Ocean is mainly assumed by the Atlantic meridional overturning circulation (AMOC), defined as the zonally integrated meridional transport in the Atlantic. It is at

\footnotetext{
* Current affiliation: Laboratoire d'Océanographie et de Climatologie par l'Éxperimentation et l'Analyse Numérique, Institut Pierre-Simon Laplace, Université Pierre et Marie Curie, Paris, France.

+ Current affiliation: Scripps Institution of Oceanography, University of California, San Diego, La Jolla, California.
}

Corresponding author address: Juliette Mignot, LOCEAN, UPMC/CNRS/IRD/MNHN, 4 place Jussieu, Case courrier 100, 75252 Paris Cedex 05, France.

E-mail: juliette.mignot@lodyc.jussieu.fr present of about $10^{15} \mathrm{~W}$ (Ganachaud and Wunsch 2000). Paleoreconstructions (McManus et al. 2004) and model studies (e.g., Ganopolski et al. 1998) suggest that this value, as well as the intensity and shape of the AMOC itself, has significantly varied in the past (see reviews by Clarke et al. 2002 and Rahmstorf 2002). Yet, the mechanisms that control its shape and strength are still under debate. In this paper, we aim at better understanding how the interior vertical diffusivity influences the AMOC in a coupled ocean-atmosphere-sea ice model.

Several recent studies suggest that the largest fraction of energy needed to explain the oceanic heat transport is provided by winds (e.g., Boccaletti et al. 2005; Gnanadesikan et al. 2005). Toggweiler and Samuels $(1993,1995)$ proposed that the entire Atlantic overturning may be sustained by wind-driven upwelling occur- 
ring in the Southern Ocean. This is in contradiction with inversion studies that yield a picture of the AMOC including nonnegligible tropical upwelling (e.g., Ganachaud and Wunsch 2000; Talley et al. 2003). Theoretical considerations and idealized model studies also point at the downward mixing of heat at low latitudes as limiting the rate of overturning in the sense of energy input (e.g., Munk and Wunsch 1998; Marotzke and Scott 1999; Huang 1999). Assuming geostrophy and advective-diffusive buoyancy balance in the pycnocline, scaling arguments suggest that the maximum strength $\Psi$ of the meridional streamfunction in the North Atlantic obeys

$$
\Psi \sim \kappa^{\alpha} \Delta \rho^{1 / 3}, \quad \alpha=2 / 3
$$

where $\kappa$ is the vertical diffusion parameter and $\Delta \rho$ is the equator-to-Pole density difference (Bryan and Cox 1967; Bryan 1987). Different exponents $\alpha$ have, however, been found in different idealized models (e.g., Colin de Verdière 1988; Hu 1996; Marotzke 1997; Zhang et al. 1999; review in Park and Bryan 2000). Using a three-dimensional global ocean general circulation model (GCM), Prange et al. (2003) found relatively good agreement with the $\alpha=2 / 3$ scaling law when taking into account the effect of vertical mixing on the density difference, although their figures suggest relatively large error bars. To our knowledge, this is the only experiment so far that has been carried out with a global ocean model, despite the possible effects of the Southern Ocean (e.g., Gnanadesikan 1999) and of the Indian and Pacific Ocean basins.

The stability of the overturning in the presence of an anomalous freshwater flux at high latitudes is also a crucial issue in climate research. Indeed, simulations of future climate scenarios predict that under increased greenhouse gas forcing, the freshwater flux into the North Atlantic Ocean will increase as a result of an intensified hydrological cycle and melting of the cryosphere. Furthermore, abrupt climate changes in the past are believed to have their origin in the response of the Atlantic MOC to an anomalous input of freshwater in the Atlantic (e.g., Rahmstorf 2002). The scaling analysis presented above, supported by modeling studies, implies that the sensitivity of the overturning to anomalous freshwater fluxes in high latitudes might be reduced in the presence of vertical mixing (e.g., Park 1999; Manabe and Stouffer 1999; Prange et al. 2003) since the initial weakening of the overturning would be counteracted by a deepening of the pycnocline. On the other hand, recent findings by Levermann and Griesel (2004) point out that one of the fundamental assumptions of this scaling-namely, the scaling of the over- turning strength to the pycnocline depth-is not necessarily valid.

Currently, the dynamics of the overturning circulation in a global coupled model remains poorly understood and its scaling behavior is largely untested. Here, we analyze the sensitivity of the Atlantic overturning to the vertical diffusivity in present-day conditions in a global coupled atmosphere-ocean-sea ice model of intermediate complexity. This is the first study that adresses this issue in a coupled model without flux adjustment. Following the ideas of Hasumi and Suginohara (1999) and measurements of Ledwell et al. (2000), the model includes a parameterization of enhanced oceanic mixing over topography and is dependent on the stratification of the water column. In addition, special care has been taken to minimize the numerical diffusivity by implementing a low-diffusive advection scheme. This point is crucial for our attempt to investigate the sensitivity to the mixing coefficient. As a result, we propose a simple decomposition of the MOC into physical components that could be used as a framework for further sensitivity studies of the MOC to vertical mixing.

The paper is organized as follows: the model and the experiments are described in section 2, the sensitivity of the AMOC to vertical diffusivity in the model is presented in section 3 . In section 4 , this sensitivity is discussed in more detail by decomposing the AMOC strength into three physical components: 1 ) outflow toward the Southern Ocean at $30^{\circ} \mathrm{S}, 2$ ) diffusion-driven upwelling in the Atlantic, and 3) wind-dependent upwelling along the boundaries. Results are discussed and conclusions are given in section 5 .

\section{Model description and experimental setup}

The model used in this study is Climate and Biosphere Group (CLIMBER)-3 $\alpha$, described by Montoya et al. (2005). It consists of the atmospheric model Potsdam Statistical Dynamical Atmospheric Model (POTSDAM)-2 (Petoukhov et al. 2000) coupled to a global, 24-layer ocean GCM based on the Geophysical Fluid Dynamics Laboratory (GFDL) Modular Ocean Model (MOM-3) code and coupled to the dynamic and thermodynamic sea ice module of Fichefet and Maqueda (1997). The oceanic horizontal resolution is $3.75^{\circ} \times 3.75^{\circ}$. A second-order-moment advection scheme (Prather 1986) was implemented for the tracers in order to minimize numerical diffusivity. This scheme is widely used in the atmospheric science community and has low diffusion relative to traditional advection schemes such as flux-corrected transport (FCT) and quadratic upstream interpolation for convective kinematics (QUICK) (Hofmann and Maqueda 2006). 
The mixing explicitly imposed in the ocean model is thus the one effectively felt by the circulation. Our study is mainly based on the analysis of 10 experiments that differ only in the value of the background vertical diffusion coefficient $\kappa$, set successively to $\kappa=0.05,0.1$, $0.2,0.3,0.4,0.5,0.6,0.75,1$, and $1.5 \mathrm{~cm}^{2} \mathrm{~s}^{-1}$. In six additional experiments, $\kappa$ was kept fixed to the low value $\kappa=0.1 \mathrm{~cm}^{2} \mathrm{~s}^{-1}$ poleward of $40^{\circ}$ and set, respectively, to $\kappa^{\text {lowlat }}=0.3,0.5,0.6,0.75,1$, and $1.5 \mathrm{~cm}^{2} \mathrm{~s}^{-1}$ in the rest of the ocean. In addition to this background vertical diffusivity, all the runs include a parameterization of boundary-enhanced mixing, with vertical diffusivities depending both on near-bottom stratification and roughness of the topography, as suggested by Hasumi and Suginohara (1999) and by the measurements of Ledwell et al. (2000) (see Montoya et al. 2005). Furthermore, the model uses the $K$-profile parameterization (KPP) scheme introduced by Large et al. (1994). The effective mixing $\kappa^{*}$ felt by the ocean thus differs from the background value $\kappa$ primarily in the mixed layer and over rough topography. The difference between the two is less than $10 \%$ in the ocean interior (Fig. 1). No grid-based horizontal diffusion is imposed, but an isopycnal diffusion with a coefficient of $\kappa_{\text {iso }}=$ $1000 \mathrm{~m}^{2} \mathrm{~s}^{-1}$ is applied. An eddy-induced tracer advection following Gent and McWilliams (1990) was implemented using the skew flux representation of Griffies (1998) with a thickness diffusion coefficient of $\kappa_{\mathrm{gm}}=$ $250 \mathrm{~m}^{2} \mathrm{~s}^{-1}$. The sensitivity of the overturning to this parameterization is investigated in a separate study by Griesel and Maqueda (2006). To focus on the effect of changes in vertical mixing, the wind stress is prescribed from the National Centers for Environmental Prediction-National Center for Atmospheric Research (NCEP-NCAR) reanalysis (Kalnay et al. 1996). Note, however, that the wind velocity itself and the buoyancy fluxes do depend on the surface temperatures, in a very similar way to that in classic coupled GCMs. The POTSDAM-2 model is based on the assumption of a universal vertical structure of temperature and humidity, which allows for the reduction of the threedimensional description to a set of two-dimensional, vertically averaged prognostic equations for temperature and humidity but also allows full coupling with the ocean surface. The reader is referred to Montoya et al. (2005) for an explicit description of the coupling. Additional experiments were performed with the same model to test the sensitivity of the results to winds in the North Atlantic. Their setup will be described in detail in section 4c. All the runs presented below were integrated starting from the Levitus (1982) temperatures and salinities, with velocities, atmospheric tem-

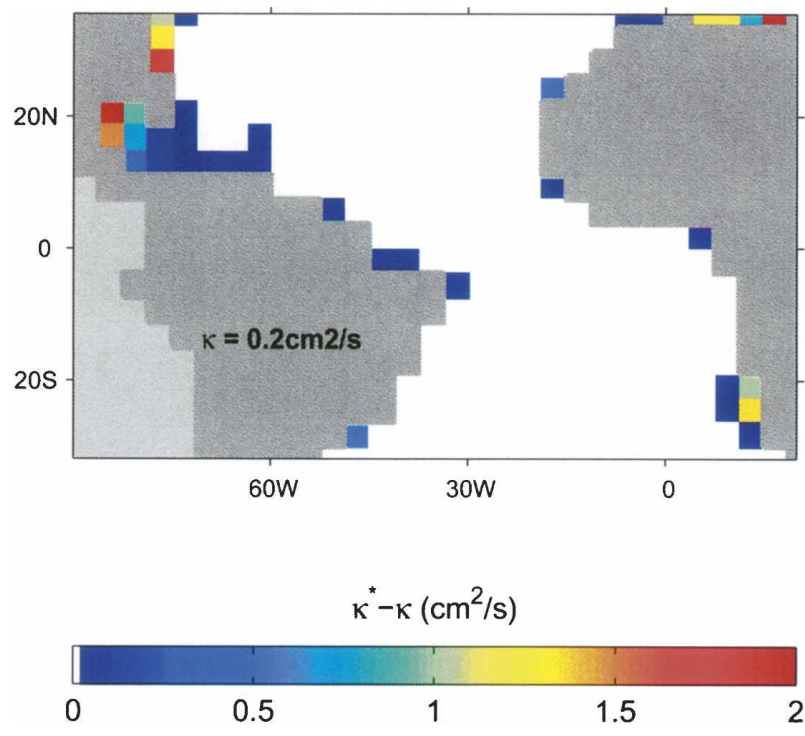

FIG. 1. Difference between the background value $\kappa$ and the effective value $\kappa^{*}$ of vertical diffusivity at $600 \mathrm{~m}$ for the run using $\kappa=0.2 \mathrm{~cm}^{2} \mathrm{~s}^{-1}$.

perature, and specific humidity set to zero, and without initial sea ice coverage. They were run for more than $2000 \mathrm{yr}$ without flux adjustments.

\section{Sensitivity of the AMOC to vertical diffusivity}

Figure 2 (top panel) shows the mean meridional streamfunction in the standard version of the model with a background vertical diffusivity $\kappa=0.1 \mathrm{~cm}^{2} \mathrm{~s}^{-1}$. This value is smaller than is generally used in coupled models of similar resolution. It corresponds to estimates in the ocean interior based on observations of turbulence (Gregg 1989), tracer release experiments (Ledwell et al. 1993), and internal wave processes (Toole et al. 1994). The zonally integrated streamfunction is in good qualitative agreement with observations (Talley et al. 2003; Ganachaud and Wunsch 2000), despite a rather weak maximum value: about $12 \mathrm{~Sv}$ $\left(\mathrm{Sv} \equiv 10^{6} \mathrm{~m}^{3} \mathrm{~s}^{-1}\right)$ of warm water flow northward in the upper ocean, sink in the Nordic and Irminger seas, and return southward at depth (below about $700 \mathrm{~m}$ ) as North Atlantic Deep Water (NADW). Given the coarse resolution of the model, the amount of overflow of dense water masses over the ridges between Greenland and Scotland is rather well represented (Dickson and Brown 1994). Note that there is no deep water formation in the Labrador Sea because of its narrowness, as detailed in Montoya et al. (2005). The NADW cell reaches a depth of roughly $2300 \mathrm{~m}$, which is rather shallow as compared with observations, and the 4-Sv inflow of Antarctic Bottom Water (AABW) at the bot- 

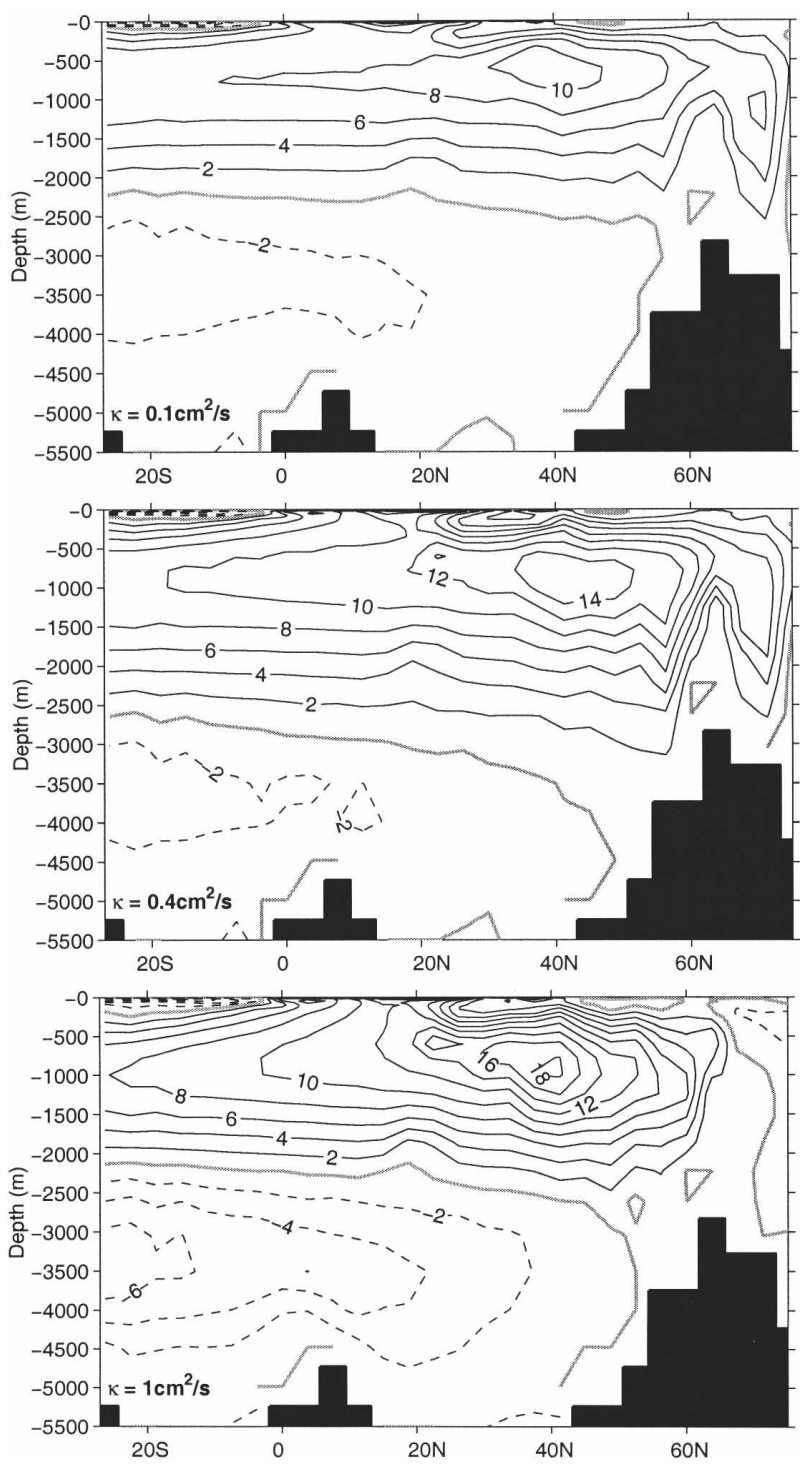

FIG. 2. Mean Atlantic overturning circulation in the run using $\kappa=$ (top) 0.1, (middle) 0.4 , and (bottom) $1 \mathrm{~cm}^{2} \mathrm{~s}^{-1}$. The contour interval is $2 \mathrm{~Sv}$. Continuous (dashed) contours are for positive (negative) values. The thick line is for 0 .

tom of the Atlantic is on the contrary relatively thick (Talley et al. 2003).

Both the shape (Fig. 2) and magnitude (Fig. 4) of the AMOC are sensitive to the background value of the vertical diffusivity $\kappa$. Figure 2 shows that the broad upwelling in the Atlantic interior increases with $\kappa$, consistently with a vertical advection-diffusion balance. This increased upwelling also appears clearly in Fig. 3, showing the meridional overturning computed in $\sigma_{0}$ coordinates and thus highlighting the water mass transformations and intensified mixing in the Atlantic interior. The overflow over the Greenland-Scotland ridge first increases with $\kappa$, as well as the depth of the NADW (cf.
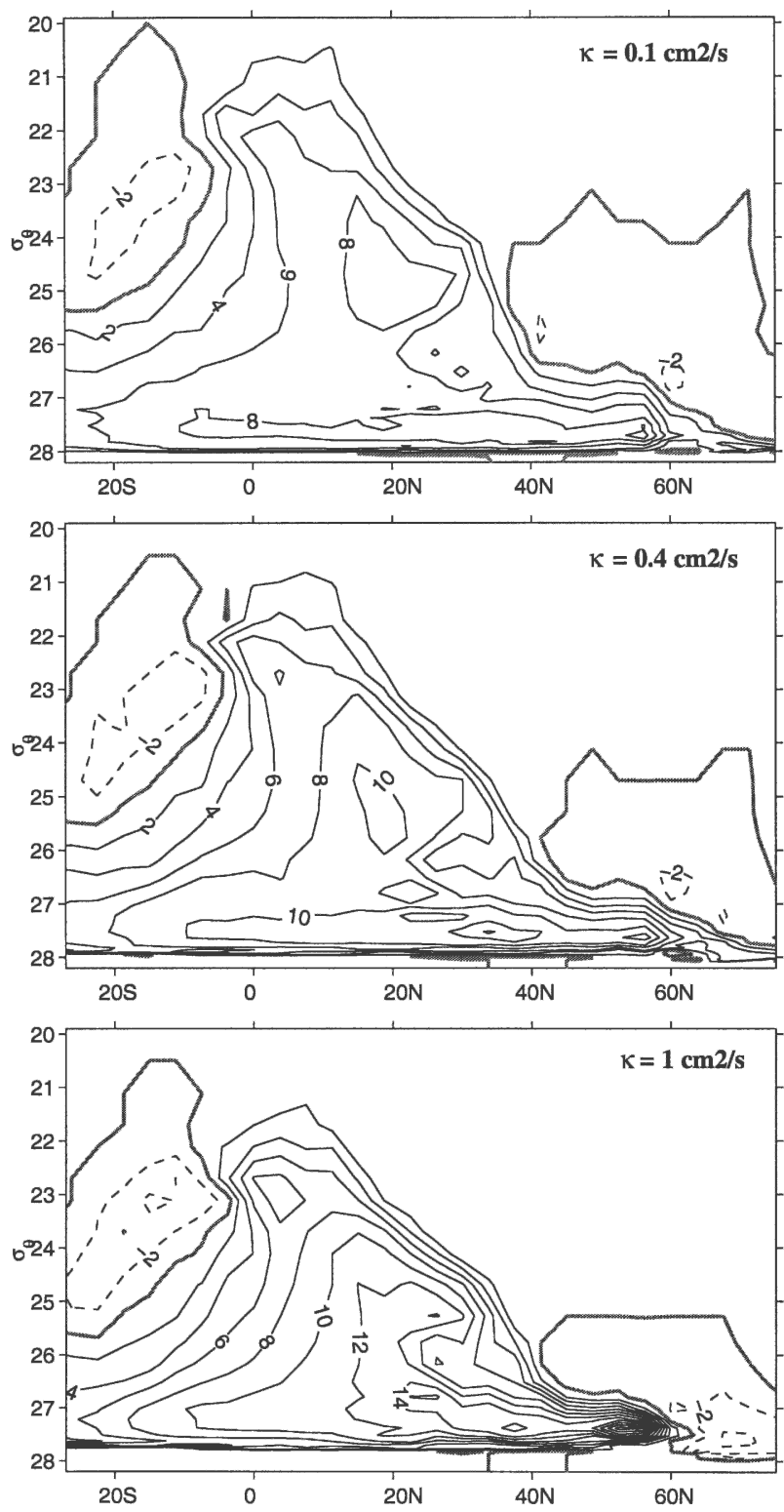

FIG. 3. As in Fig. 2 but for overturnings computed and plotted as a function of density. Overturning with $\sigma_{0}$ coordinates is computed with 39 unequally spaced density intervals that give higher resolution for higher $\sigma_{0}$. The contour interval is $2 \mathrm{~Sv}$. Continuous (dashed) contours are for positive (negative) values. The thick line is for 0 .

Fig. 2, top and middle panels), while at high vertical diffusivities, the overflow vanishes and the depth reached by the NADW decreases again (Fig. 2, bottom). The maximum density of the water mass formed in the high latitudes as shown in Fig. 3 exhibits a similar dependency at high vertical diffusivities. Deep convection then primarily takes place in the Irminger Sea, south of the ridges, rather than in the Nordic seas. In Fig. 4, we plot the maximum $M_{\max }$ of the streamfunc- 


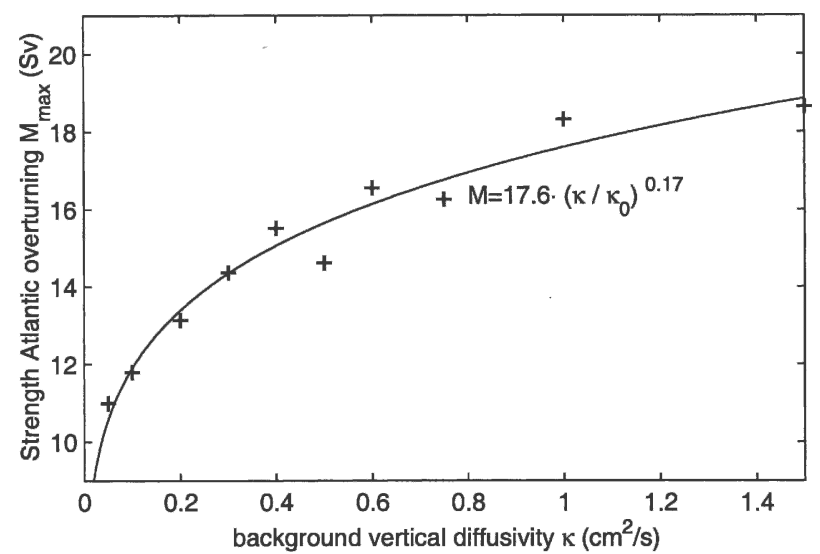

FIG. 4. Maximum Atlantic overturning against background vertical diffusivity in the standard configuration. The line shows the least squares fit by a power law $\left(\kappa_{0}=1 \mathrm{~cm}^{2} \mathrm{~s}^{-1}\right)$.

tion computed in depth coordinates in the domain $\left(25^{\circ}-\right.$ $\left.70^{\circ} \mathrm{N}, 500-5000 \mathrm{~m}\right)$. It is reached between $600-$ and $1000-\mathrm{m}$ depth and between $37^{\circ}$ and $45^{\circ} \mathrm{N}$ in all the runs. Generally, $M_{\max }$ increases with vertical diffusivity, in agreement with numerous previous modeling studies (e.g., Bryan 1987; Colin de Verdière 1988; Marotzke 1997). Exceptions are the runs using $\kappa=0.5 \mathrm{~cm}^{2} \mathrm{~s}^{-1}$ and $\kappa=0.75 \mathrm{~cm}^{2} \mathrm{~s}^{-1}$, which play a special role due to changes in the deep convection sites, as will be explained below. For vertical diffusivity of less than $\kappa=$ $0.5 \mathrm{~cm}^{2} \mathrm{~s}^{-1}$, the increase appears to be linear, and a change of regime seems to occur for $\kappa \geq 0.5 \mathrm{~cm}^{2} \mathrm{~s}^{-1}$. Very similar results are obtained with the density-space streamfunction.

To compare with previous studies, we give here the least squares fit of the points in Fig. 4 with a power law. The coefficient $\alpha=0.17$ is much weaker than the $2 / 3$ suggested by simple scaling arguments in a onehemispheric configuration. It is increased to $\alpha=0.35$ when fitting the maximum of the overturning in density coordinates (see Park and Bryan 2000 and Klinger et al. 2003 for a discussion), which is still weaker than the scaling prediction. That is because several additional processes that are not considered in the derivation of Eq. (1) can have an effect in a global coupled model. In particular, in a one-hemispheric configuration, the water masses that sink at high latitudes necessarily upwell in the Atlantic basin. This differs from the real ocean and a global model, in which part of the flow can be exported toward the Southern Ocean at $30^{\circ} \mathrm{S}$. To discuss the effect of diffusion, it is thus helpful to distinguish the large-scale upwelling $W_{\text {Atl }}(\mathrm{Sv})$ taking place in the Atlantic basin between the latitude of maximum overturning and $30^{\circ} \mathrm{S}$ from the total maximum overturning $M_{\text {max }}$. We define

$$
W_{\text {Atl }}=M_{\max }-M_{S},
$$

where $M_{S}$ is the outflow of water into the Southern Ocean at $30^{\circ} \mathrm{S}$. The latter can be determined directly as the maximum value of the meridional streamfunction at $30^{\circ} \mathrm{S}$. The ratio $R=M_{S} / M_{\max }$ gives a measure for the interhemispheric transport efficiency of the Atlantic overturning. If it is zero, there is no southern outflow of NADW and the overturning is limited to the Atlantic basin. If $R=1$, the total amount of water downwelling in the northern North Atlantic is exported to the Southern Ocean. Recent computations from Talley et al. (2003) suggest that $R=78 \pm 10 \%$ in the real ocean while values inferred from state-of-the-art coupled GCMs that are tuned to represent the present climate as realistically as possible are subject to larger uncertainty (Table 1). Understanding the sensitivity of largescale quantities such as $R$ or $M_{\max }$ is of primary importance both for the full comprehension of the role of the ocean in climate and for the evaluation of climate models. Because of computational costs, however, the numerous experiments that it requires cannot be afforded with state-of-the-art GCMs. This can be done in coupled model of intermediate complexity, such as CLIMBER-3 $\alpha$. In the following, we examine successively the sensitivity of $M_{S}$ and $W_{\text {Atl }}$ to the background

TABLE 1. Estimates of the efficiency $R$ in a selection of state-of-the-art global coupled GCMs. When the values were inferred from a figure, the number of the figure is indicated and an error bar was estimated according to the contour level used by the authors. The horizontal ocean resolution is indicated in brackets for each model [European Centre for Medium-Range Weather Forecasts-Hamburg Model (ECHAM); Large-Scale Geostrophic Ocean Model (LSG); Ocean Isopycnal Model (OPYC); Bergen Climate Model (BCM); Third Hadley Centre Coupled Ocean-Atmosphere General Circulation Model (HadCM3)].

\begin{tabular}{llccc}
\hline \hline Model (horizontal ocean resolution) & & $M_{\max }(\mathrm{Sv})$ & $M_{S}(\mathrm{~Sv})$ & Ratio $R(\%)$ \\
\hline GFDL $\left(4.5^{\circ}\right.$ lat $\times 3.7^{\circ}$ lon $)$ & Delworth et al. (1993, Fig. 3) & $19 \pm 1$ & $11 \pm 1$ & $58 \pm 8$ \\
ECHAM3-LSG $\left(4^{\circ}\right)$ & Timmermann et al. (1998, Fig. 4) & $30 \pm 2$ & $18 \pm 2$ & $60 \pm 10$ \\
ECHAM4-OPYC3 $\left(2.8^{\circ}\right)^{*}$ & Latif et al. (2000) & 23 & 65 \\
BCM $\left(2.4^{\circ}\right)^{*}$ & Furevik et al. (2003) & 18 & 15 & 77 \\
HadCM3 $\left(1.25^{\circ}\right)$ & Vellinga and Wu (2004, Fig. 1) & $19 \pm 1$ & $15 \pm 1$ \\
GFDL $\left(1^{\circ}\right)$ & Delworth et al. (2006) & $23.9 \pm 1.3$ & $18.1 \pm 1.0$ & $80 \pm 10$ \\
\hline
\end{tabular}

* The meridional resolution in ECHAM4-OPYC3 and BCM is increased in the tropical area. 


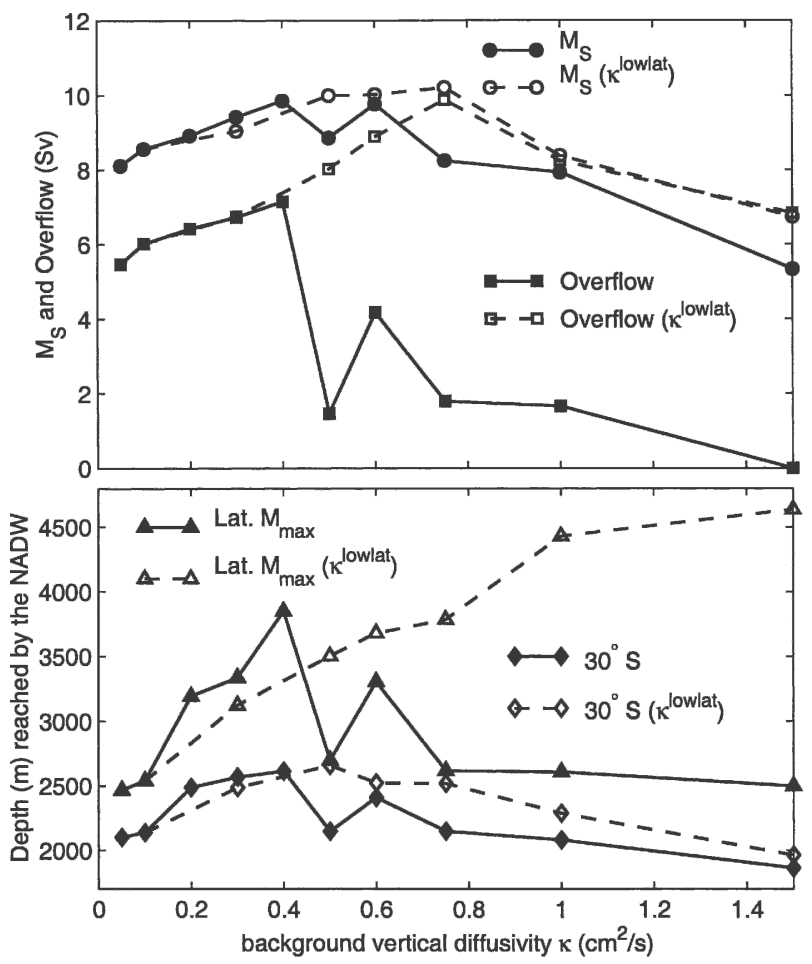

FIG. 5. (top) Southern Ocean outflow of NADW (maximum of the meridional streamfunction at $30^{\circ} \mathrm{S}$, circles) and overflow over the Greenland-Scotland ridge (maximum of the meridional streamfunction between $65^{\circ}$ and $70^{\circ} \mathrm{N}$, squares) in the standard configuration (continuous lines) and in the runs using $\kappa^{\text {lowlat }}$ (dashed lines). (bottom) Maximum depth (m) reached by the NADW at the latitude of AMOC maximum in the North Atlantic (triangles) and at $30^{\circ} \mathrm{S}$ (diamonds) in the standard configuration (continuous lines) and in the runs using $\kappa^{\text {lowlat }}$ (dashed lines).

vertical diffusivity $\kappa$. Our aim is to decompose the AMOC into distinct components that correspond to different physical processes with different sensitivities to vertical mixing.

\section{A decomposition of the AMOC}

\section{a. Outflow at $30^{\circ} \mathrm{S}$ and deep convection}

Figure 5 (top panel) shows that the part of the NADW flow that is exported toward the Southern Ocean at $30^{\circ} \mathrm{S}, M_{S}$, is only weakly sensitive to the background vertical diffusivity. It varies by less than $2 \mathrm{~Sv}$ for $\kappa$ ranging from 0.05 to $1.0 \mathrm{~cm}^{2} \mathrm{~s}^{-1}$. It increases linearly but very slowly with increasing values up to $\kappa=0.4$ $\mathrm{cm}^{2} \mathrm{~s}^{-1}$, is weak for $\kappa=0.5 \mathrm{~cm}^{2} \mathrm{~s}^{-1}$, recovers a higher value for $\kappa=0.6 \mathrm{~cm}^{2} \mathrm{~s}^{-1}$, and then decreases again for higher coefficients. This variation is robust to the use of density coordinates and correlates very well with the intensity of deep convection in the Nordic seas. The sensitivity of the latter to vertical diffusivity has already been observed in Fig. 2. For $\kappa \leq 0.4 \mathrm{~cm}^{2} \mathrm{~s}^{-1}$, as well as for $\kappa=0.6 \mathrm{~cm}^{2} \mathrm{~s}^{-1}$, deep convection takes place primarily in the Nordic seas, inducing the circulation cell north of the Greenland-Scotland ridge visible in Fig. 2 (top and middle panels). For $\kappa=0.5 \mathrm{~cm}^{2} \mathrm{~s}^{-1}$ and $\kappa \geq$ $0.75 \mathrm{~cm}^{2} \mathrm{~s}^{-1}$, on the other hand, deep mixing takes place exclusively in the Irminger Sea, that is, south of the ridges, and the circulation north of the latter vanishes (Fig. 2, bottom panel). Figure 5 (top panel) shows that the intensity of the vertical circulation cell north of the Greenland-Scotland ridge, eventually entering the Atlantic basin through the overflow, correlates very well with the amount of NADW exported toward the Southern Ocean. The shift of deep convection location with increasing $\kappa$ is primarily due to two combined effects. First, intense mixing in the high latitudes, in particular in the Irminger Sea, tends to homogenize the water column locally, favoring deep convection. Second, increased vertical diffusivities lead to an increased mixing in the Atlantic interior and thus to a stronger decrease of the vertical density difference between upper and lower water masses along the path to the convection sites. This favors deep convection earlier along this path. Note that in both cases, deep convection is then preferably shifted to the Irminger Sea since it is also an area of intense cooling and doming of isopycnals and thus preconditioned for deep convection. Relatively deep mixing is occurring in this area even in the standard run using $\kappa=0.1 \mathrm{~cm}^{2} \mathrm{~s}^{-1}$, as shown in Montoya et al. (2005). These two effects can be illustrated through the analysis of additional simulations where high values of mixing are imposed equatorward of $40^{\circ}$ latitude only, with $\kappa$ fixed to a low value of $\kappa=$ $0.1 \mathrm{~cm}^{2} \mathrm{~s}^{-1}$ at higher latitudes. Here, $M_{S}$ and the magnitude of the overflow are almost identical in the runs $\kappa^{\text {lowlat }}=0.3 \mathrm{~cm}^{2} \mathrm{~s}^{-1}$ and $\kappa=0.3 \mathrm{~cm}^{2} \mathrm{~s}^{-1}$, while deep convection north of the ridges is reestablished for $\kappa^{\text {lowlat }}$ $=0.5 \mathrm{~cm}^{2} \mathrm{~s}^{-1}$ and $\kappa^{\text {lowlat }}=0.75 \mathrm{~cm}^{2} \mathrm{~s}^{-1}$ as compared with the standard runs, and it is enhanced for $\kappa^{\text {lowlat }}=$ $0.6 \mathrm{~cm}^{2} \mathrm{~s}^{-1}$ (Fig. 5, top panel, dashed lines). Overflow above the northern ridges and outflow at $30^{\circ} \mathrm{S}$ are then both increased. The situation changes for $\kappa^{\text {lowlat }} \geq 1.0$ $\mathrm{cm}^{2} \mathrm{~s}^{-1}$ where overflow and outflow decrease again because of the second effect described above. Note that the transition is not sharp. During spinup, the run using $\kappa=0.6 \mathrm{~cm}^{2} \mathrm{~s}^{-1}$ exhibits intermittent shifts between the two sinking regions before steady state is established with a significant amount of deep water formed in the Nordic seas (not shown). The transition thus occurs in the interval $\kappa \in\left[0.5-0.6 \mathrm{~cm}^{2} \mathrm{~s}^{-1}\right]$, suggesting that other effects such as atmospheric feedbacks play a role.

To further document the link between the location of deep convection at high latitudes and the outflow at $30^{\circ} \mathrm{S}$, we plot in Fig. 5 (bottom panel) the maximal 


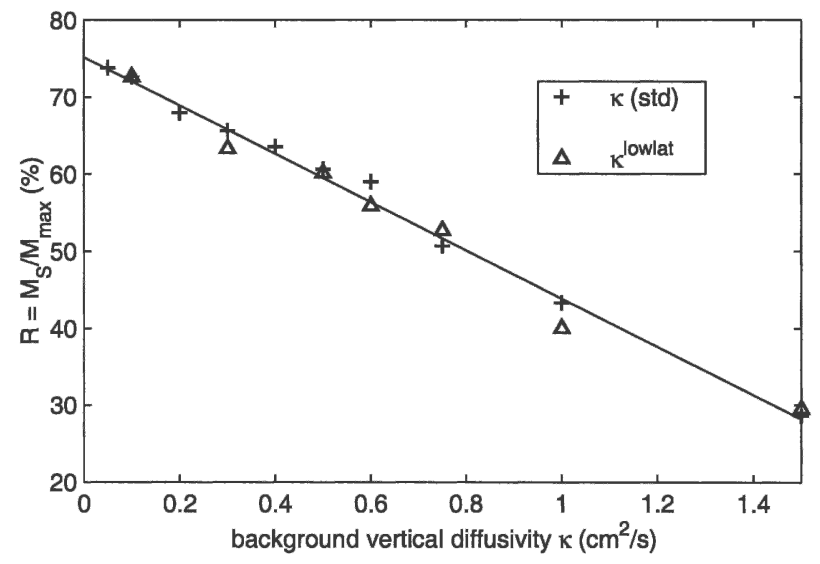

FIG. 6. Ratio $R=M_{S} / M_{\max }$ as a function of the background vertical diffusivity $\kappa$. Crosses correspond to the standard runs and triangles to the runs using $\kappa^{\text {lowlat }}$. The straight line represents a linear fit of the data.

depth reached by the NADW at the latitude of maximum overturning and at $30^{\circ} \mathrm{S}$. At each of these two latitudes, the depth is diagnosed where the meridional streamfunction is zero. In the standard runs, it is strongly correlated with the deep convection location, showing that when deep convection takes place in the Nordic seas NADW is denser and reaches higher depths and a larger fraction is exported southward. This correlation still holds at the latitude of maximum overturning in the runs using $\kappa^{\text {lowlat }}$. At $30^{\circ} \mathrm{S}$, however, this depth saturates for $\kappa^{\text {lowlat }}=0.5 \mathrm{~cm}^{2} \mathrm{~s}^{-1}$, and decreases again when further increasing $\kappa^{\text {lowlat }}$, as a result of intense mixing in the Atlantic interior. We investigate this component in detail in the next section.

It is beyond the scope of this paper to analyze the fate of the NADW exported at $30^{\circ} \mathrm{S}$. Upwelling in the Southern Ocean as a result of wind forcing in the Drake Passage (Toggweiler and Samuels 1995) and mixing with the Circumpolar Deep Water around Antarctica to finally upwell in the Indo-Pacific under the action of mixing are possible processes that would need to be investigated in a separate study. Hints can, however, be found in the analysis of the ratio $R=M_{S} / M_{\max }$ introduced above. In CLIMBER-3 $\alpha, R$ decreases linearly with increasing vertical diffusivity (Fig. 6) and is almost unaffected by restricting the increase of background vertical diffusivity to low latitudes $\left(\kappa^{\text {lowlat }}\right.$, Fig. 6). Thus, $M_{\max }$ increases faster than $M_{S}$ with increasing $\kappa$. This suggests that vertical diffusion is most effective in controlling the strength of the overturning in the Atlantic midlatitudes and Tropics and allows us to speculate that mixing in the Indo-Pacific probably plays a minor role. The decrease of the efficiency ratio $R$ with $\kappa$ differs from Prange et al. (2003) who find that $R$ is constant around 0.75 in their three-dimensional forced global ocean GCM with changing vertical diffusivities. The values obtained in CLIMBER-3 $\alpha$ are in the range of other GCMs for $\kappa \leq 0.4 \mathrm{~cm}^{2} \mathrm{~s}^{-1}$ and become lower for larger $\kappa$ (cf. Table 1$)$. This suggests that realistic values of $\kappa$ are in this interval. For $\kappa \geq 0.75 \mathrm{~cm}^{2} \mathrm{~s}^{-1}, R \leq 50 \%$; that is, more than half of NADW upwells in the Atlantic.

\section{b. Advection-diffusion balance}

We investigate now the sensitivity of the Atlantic upwelling $W_{\text {Atl }}$ to the background vertical diffusivity (Fig. 7). By definition $W_{\text {Atl }}$ corresponds to the total upwelling $W_{w}$ taking place in the Atlantic calculated by $W_{w}=\iint_{\mathcal{D}} w d x d y$, where $w$ is the vertical velocity given by the model and $\mathcal{D}$ is the Atlantic oceanic domain extending from $30^{\circ} \mathrm{S}$ to the latitude of the maximum of the overturning, around $40^{\circ} \mathrm{N}$. Note that $W_{w}$ is still a function of depth. We define the level of no horizontal motion as the depth at which $W_{w}=W_{\text {Atl }}$, and all following diagnostics will be shown at this level. This level lies between 600 and $1000 \mathrm{~m}$ in all the experiments, which corresponds well to the level of maximum overturning in the North Atlantic.

The fit of $W_{\text {Atl }}$ by a power law $W=W_{1}\left(\kappa / \kappa_{0}\right)^{\alpha}$ yields a coefficient $\alpha=0.59$. This value is quite close to the $2 / 3$ power law of Eq. (1). However, it implies that the Atlantic upwelling reaches zero for no vertical diffusivity, which does not seem to be the case in Fig. 7. The fit with a constant offset $W=W_{1}\left(\kappa / \kappa_{0}\right)^{\alpha}+W_{0}$, as shown in Fig. 7, rather suggests a linear increase of $W_{\text {Atl }}$ with $\kappa$, with a slope of $7.3 \mathrm{~Sv}$. This linearity is consistent with Toggweiler and Samuels's (1998) findings using an earlier global version of MOM, although they obtained a much stronger slope (of about $23 \mathrm{~Sv} \mathrm{~cm}^{-2} \mathrm{~s}$ ). We speculate that the difference results from their use of restoring boundary conditions, which allows for strong coupling between the circulation and freshwater fluxes and therefore a stronger effect of mixing from the surface to the deep ocean. A constant offset of $W_{0}=2.5 \mathrm{~Sv}$ is found in the limit of zero background vertical diffusivity, assuming that the linearity holds down to this limit. Very similar results are again obtained with the densitycoordinate streamfunction (not shown).

The scaling law of Eq. (1) was based on the assumption of a balance between the upwelling of dense waters and vertical diffusion at the base of the thermocline. Locally, this balance can be written as

$$
w_{\mathrm{AD}}(x, y, z) \partial_{z} \rho(x, y, z)=\partial_{z}\left[\kappa^{*}(x, y, z) \partial_{z} \rho(x, y, z)\right],
$$




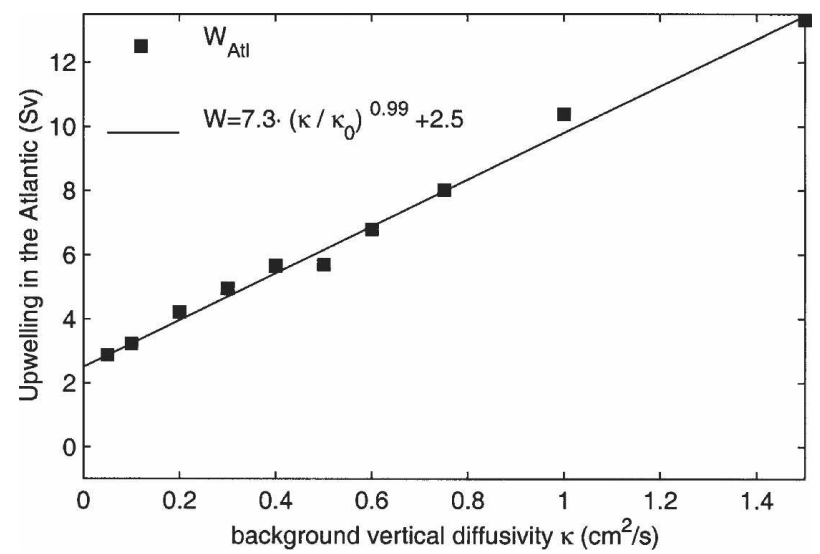

FIG. 7. Upwelling in the Atlantic diagnosed as $W_{\text {Atl }}=M_{\max }-$ $M_{S}$. The line shows the result of a least squares fit $\left(\kappa_{0}=\right.$ $\left.1 \mathrm{~cm}^{2} \mathrm{~s}^{-1}\right)$.

where $w_{\mathrm{AD}}$ is the vertical advection velocity induced by diffusion of waters with the density $\rho$; $\kappa^{*}$ is the local vertical diffusivity in the model. It is a function of the three dimensions $(x, y$, and $z$ ) because of the parameterizations of enhanced mixing over topography and KPP (see section 2). Note that the applicability of Eq. (3) is not trivial. Especially, as is pointed out by Munk and Wunsch (1998), it is based on the strong assumption that vertical diffusion of temperature and salinity are indeed both balanced by the same advection. It therefore also assumes a linear equation of state. We will show, however, that it is justified for the large-scale upwelling within the entire basin. Vertical advection velocity $w_{\mathrm{AD}}$ is plotted in Fig. 8 for the run using $\kappa=0.4 \mathrm{~cm}^{2} \mathrm{~s}^{-1}$ together with the vertical velocity $w$ given by the model, at the level of no motion. Vertical velocity $w$ is diagnosed by the continuity equation and is therefore very noisy. In Fig. 8, it has been smoothed by averaging each grid cell with the nearest points but remains noisy, while $w_{\mathrm{AD}}$ results from the density field and is therefore much smoother. Both fields clearly show a large-scale upwelling in the interior of the Atlantic, strongest along the subtropical gyre circulation and along the path of incoming waters in the Southern Hemisphere, where vertical density gradients are largest. Figure 9 compares the integrated upwellings computed from $w$ and from $w_{\mathrm{AD}}$ in the Atlantic interior, that is, without taking the grid points adjacent to the coast into account, for the different runs. The very good agreement suggests that the one-dimensional balance in Eq. (3) is indeed a good approximation of the large-scale upwelling taking place in the ocean interior in the model. At the basin boundaries, and especially along the western boundary, a strong upwelling is revealed by $w$ but is not captured by $w_{\mathrm{AD}}$ (Fig. 8). Additional processes that will be discussed below significantly contribute to the upwelling there.

To quantify the total contribution of the upwelling induced by the background diffusivity only to the total Atlantic upwelling, we now compute the integral

$$
W_{\mathrm{AD}}=\kappa \iint_{\mathcal{D}} \frac{\partial_{z}^{2} \rho}{\partial_{z} \rho} d x d y
$$

over the whole domain $\mathcal{D}$. In the interior of the basin, this is justified by the fact that the difference between

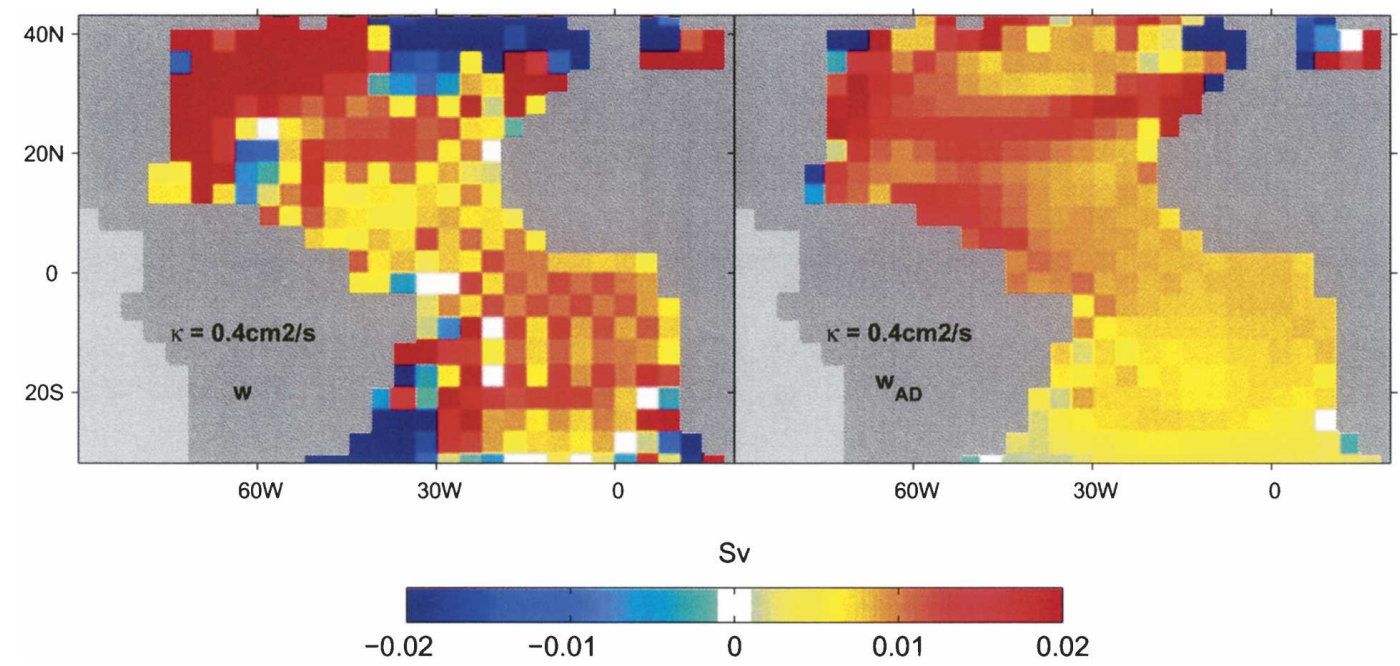

FIG. 8. (left) Total vertical velocity $w$ given by the model and (right) advection velocity induced by diffusion of waters $w_{\mathrm{AD}}$ [Eq. (3)] at the level of no motion $(780 \mathrm{~m})$ for the run using $\kappa=0.4 \mathrm{~cm}^{2} \mathrm{~s}^{-1}$. The figure is restricted to the domain $\mathcal{D}$. Both fields are weighted by the area of each grid cell and thus are expressed in Sverdrups. 


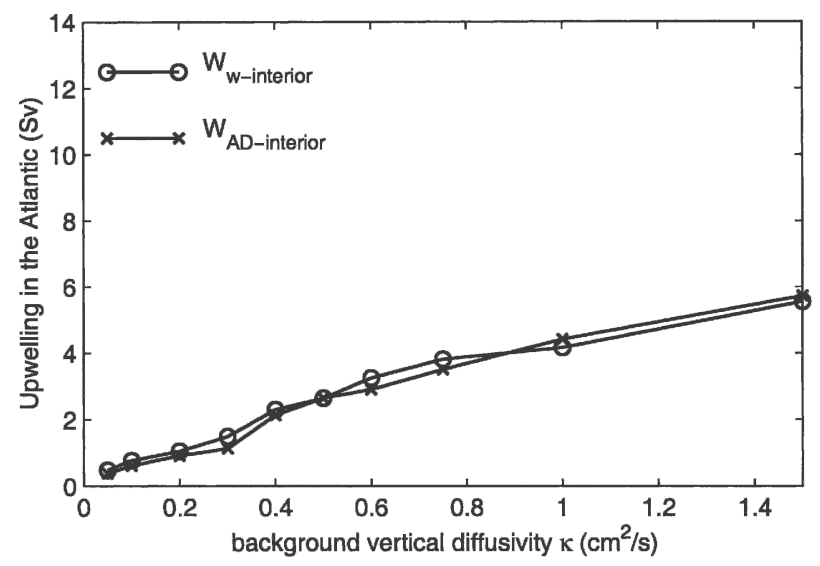

FIG. 9. Upwelling in the Atlantic interior diagnosed from the vertical velocity $w$ of the model $\left(W_{w-\text { interior }}\right)$ and from the advection-diffusion balance (3) $\left(W_{\mathrm{AD}-\text { interior }}\right)$.

$\kappa^{*}$ and $\kappa$ is weak (Fig. 1). The effect of $\kappa^{*}$ at the boundaries will be quantified below. We show $W_{\mathrm{AD}}$ in Fig. 10 . It increases linearly with $\kappa$ and extrapolates to the origin. The linearity differs from immediate results of the scaling law in Eq. (1), which is based, as are all of the classic scaling laws for the meridional overturning (Bryan 1987; Gnanadesikan 1999; Park 1999; Park and Bryan 2000), on the geostrophic thermal wind balance, which, together with the continuity condition, yields

$$
W_{\mathrm{AD}}=\frac{g \Delta \rho D^{2}}{\rho_{0} \varepsilon},
$$

where $g$ is the gravity constant, $\rho_{0}$ is a reference density, $D$ is the pycnocline depth, and $\varepsilon$ is a geometry factor. The assumption that is usually made is that both $\varepsilon$ and $\Delta \rho$ are constant, and variations of $W_{\mathrm{AD}}$ are analyzed with regard to variations of $D$. This differs from our model results where the pycnocline depth $D$ is practi-

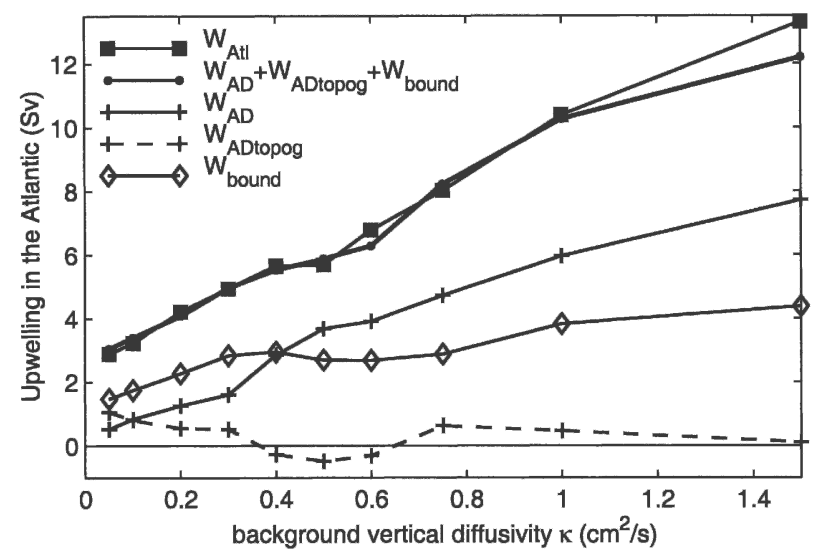

FIG. 10. Decomposition of the Atlantic upwelling into physical components. cally constant (Fig. 11, left panel), while the meridional density gradient $\Delta \rho$ increases linearly with $\kappa$ up to $\kappa=$ $1 \mathrm{~cm}^{2} \mathrm{~s}^{-1}$ (Fig. 11, right panel). Note that $\Delta \rho$ is here considered at the grid point closest to the level of no motion and the pycnocline depth (Fig. 11, left panel) in the different runs, that is, $680 \mathrm{~m}$, but the linearity is very robust and verified at any vertical levels [see Griesel and Maqueda (2006) for further details]. Taking the variation of $\Delta \rho$ with $\kappa$ into account, the scaling Eq. (1) can be reduced to

$$
\Psi \sim \kappa^{2 / 3} \Delta \rho^{1 / 3} \sim \kappa^{2 / 3} \kappa^{1 / 3}=\kappa,
$$

in agreement with the linearity found in Fig. 10. (For the run using $\kappa=1.5 \mathrm{~cm}^{2} \mathrm{~s}^{-1}$, the mixing is too strong to sustain a tracer distribution comparable to observations.) The fact that the pycnocline depth $D$ is independent of $\kappa$ (Fig. 11, left panel) is also consistent with the scaling $D \sim(\kappa / \Delta \rho)^{1 / 3}$ implied by Eq. (1) (e.g., Park and Bryan 2000) when accounting for the linear relation between $\Delta \rho$ and $\kappa$.

Our findings are thus consistent with the previous scalings, but they point out that the meridional density difference may not be assumed constant in coupled simulations. Most of the studies previously dedicated to the verification of scaling laws have been carried out using forced oceanic GCMs, where the restoring surface boundary conditions might prevent the meridional density gradient $\Delta \rho$ from varying significantly. The ocean is thus only free to adjust through varying its pycnocline depth. On the contrary, in our coupled simulations where only the winds are kept constant, $\Delta \rho$ varies significantly while the pycnocline depth is constant. This result is thus consistent with theories of the "ventilated thermocline," which suggest that the pycnocline depth is primarily determined by the winds (e.g., Luyten et al. 1983), in particular in the case of weak diapycnal diffusivity (Boccaletti et al. 2004). Additional experiments presented below suggest, however, that winds in the Southern Ocean might be playing the dominant role. Note finally that the shifts in deep convection location discussed above are not detected in $W_{\mathrm{AD}}$ (Fig. 10) as they were in $M_{S}$ (Fig. 5), indicating that they do not lead to significant variations in the geometric coefficient $\varepsilon$. The scaling Eq. (5) is indeed valid in the region where the southward flow of NADW is a western boundary current (WBC), which is justified merely south of $50^{\circ} \mathrm{N}$ in the model, whatever deep water formation site is favored. Thus, $\varepsilon$ can be assumed constant as in classic scalings.

In Eq. (4), the variations of $\kappa$ are not taken into account. The contribution $W_{\text {ADtopog }}$ to the upwelling due to enhanced mixing above the topography, that is 

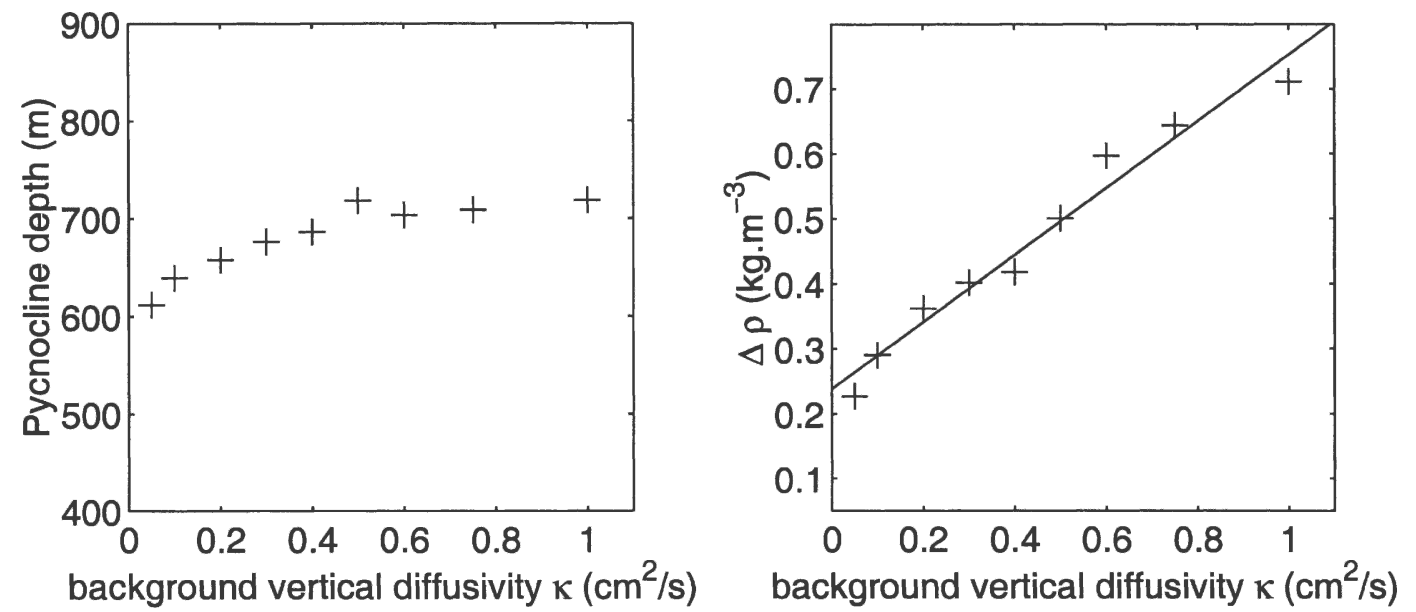

FIG. 11. (left) Pycnocline depth as defined in Park (1999) as a function of background vertical diffusivity in the standard runs. The range was taken as in Gnanadesikan (1999). (right) Density difference between the latitude bands $\left(50^{\circ}-80^{\circ} \mathrm{N}\right)$ and $\left(20^{\circ}-30^{\circ} \mathrm{N}\right)$ in the Atlantic Ocean and at $680-\mathrm{m}$ depth, as a function of background vertical diffusivity in the standard runs. The line shows the linear least squares fit.

essentially along the boundaries at this depth, is estimated by

$$
\begin{aligned}
W_{\text {ADtopog }}= & \iint_{\delta \mathcal{D}} \frac{\partial_{z}\left[\left(\kappa^{*}-\kappa\right) \partial_{z} \rho\right]}{\partial_{z} \rho} d x d y \\
= & \iint_{\delta \mathcal{D}}\left(\kappa^{*}-\kappa\right) \frac{\partial_{z}^{2} \rho}{\partial_{z} \rho} d x d y \\
& +\iint_{\delta \mathcal{D}} \partial_{z} \kappa^{*} d x d y .
\end{aligned}
$$

The integral is here only taken over grid points $\delta \mathcal{D}$ of $\mathcal{D}$ adjacent to the coast. The values for $W_{\text {ADtopog }}$ scatter between -0.5 and $1 \mathrm{~Sv}$ with no clear trend with $\kappa$ (Fig. 10). The negative contribution comes from the second term on the right-hand side in Eq. (7), as $\kappa^{*}$ increases with depth. This competes the first term on the righthand side, accounting for enhanced mixing over topography. The weakness of $W_{\text {ADtopog }}$ is consistent with findings of Hasumi and Suginohara (1999), whose simulations show that upwelling and the circulation of the deep water masses is affected by localized deep mixing but that $M_{\max }$ is insensitive to this parameterization, and with more recent modeling results from Saenko and Merryfield (2005).

The sum $W_{\mathrm{AD}}+W_{\text {ADtopog }}$ is still weaker than $W_{\mathrm{Atl}}$, indicating that not all of the upwelling $W_{\text {Atl }}$ in the Atlantic can be explained by a balance between vertical advection and diffusion. Horizontal terms in the dynamic equation of $\rho$ can, for example, be locally important, especially along the boundaries where the isopycnals are tilted. Böning et al. (1995) pointed at the up- welling in the $\mathrm{WBC}$ as being primarily responsible for the weak poleward heat transport in the Atlantic in coarse-resolution models, as it provides a shortcut for a substantial amount of NADW to upwell in the Atlantic and thus reduces the efficiency $R$ of the overturning. Veronis (1975) proposed that the upwelling of cold water along the WBC is necessary to balance the spurious cross-isopycnal fluxes due to horizontal diffusion across steeply sloping isopycnals in the WBC. This so-called Veronis effect should be weak in our model because no horizontal diffusion is imposed and numerical diffusion has been drastically reduced by the use of the lowdiffusive tracer advection scheme. However, Huck et al. (1999) and Yang (2003) demonstrated that upwelling along the boundaries can also be linked to the lateral boundary layer dynamics in coarse-resolution models, and not only to the thermodynamic Veronis effect. The upwelling along the boundaries that is not due to the vertical advection-diffusion balance can be computed as

$$
W_{\text {bound }}=\iint_{\delta \mathcal{D}} w d x d y-\iint_{\delta \mathcal{D}} \frac{\partial_{z}\left(\kappa^{*} \partial_{z} \rho\right)}{\partial_{z} \rho} d x d y .
$$

The second term on the right-hand side of Eq. (8) is the upwelling balancing the total vertical diffusion taking place along the boundaries. We show $W_{\text {bound }}$ in Fig. 10 at the same depth as the advection-diffusion upwelling $W_{\mathrm{AD}}$. Here, $W_{\text {bound }}$ is between 2 and $4 \mathrm{~Sv}$ and increases weakly with $\kappa$. The sum $W_{\text {AD }}+W_{\text {ADtopog }}+W_{\text {bound }}$ is also plotted in Fig. 10. Its very good agreement with the 
total Atlantic upwelling $W_{\text {Atl }}$ justifies a posteriori the decomposition that we present in this study and illustrates that, away from the boundaries, advectiondiffusion balance holds. Note that it is not a trivial decomposition since only one of the three terms, $W_{\text {bound }}$, is computed directly from the velocity field, and only along the coast. The other two result from the density field in combination with the strong assumption of a vertical advection-diffusion balance. The first term, $W_{\mathrm{AD}}$, is dominant and balances the background constant diffusion. It increases in first order linearly with the vertical diffusion coefficient and thereby dominates the shape of $W_{\text {Atl }}$ as a function of $\kappa$. Here, $W_{\text {ADtopog }}$ is very weak and can account either for an upwelling or a downwelling. It has no significant trend with $\kappa$. The residual term $W_{\text {bound }}$ is computed along the boundaries only. It depends weakly on $\kappa$. Its sensitivity to the wind forcing is discussed in the next section.

\section{c. Wind-dependent upwelling along the boundaries}

It can be shown that $W_{\text {bound }}$ occurs primarily in the west between $20^{\circ}$ and $40^{\circ} \mathrm{N}$. Yang (2003) suggested that upwelling at the western boundary in coarse-resolution models is directly linked to the effect of the wind stress curl on a poorly resolved western boundary layer (WBL). The latter is required not only to balance the interior Sverdrup transport to close the gyre circulation, but also to dissipate the vorticity imposed by the wind stress curl. If it is not resolved, strong spurious upwelling and downwelling develop in order to dissipate the wind-imposed vorticity by distorting some important dynamics. The width $\delta$ of the WBL is given by $\delta \approx\left(A_{H} / \beta\right)^{1 / 3}$ (Munk 1950), where $\beta$ is the meridional derivative of the Coriolis parameter and $A_{H}$ is the lateral viscosity. In the model, $A_{H}=3.2 \times 10^{5} \mathrm{~m}^{2} \mathrm{~s}^{-1}$ so that $\delta \approx 250 \mathrm{~km}$ at $30^{\circ} \mathrm{N}$, while the zonal resolution at this latitude is on the order of $360 \mathrm{~km}$. The WBL is thus poorly resolved and the effect described by Yang (2003) could be at play. In addition, because the wind stress is the same in all of our experiments described so far (prescribed to NCEP-NCAR), this would explain the approximately constant contribution of this upwelling for different values of $\kappa$. To further investigate this mechanism, we set additional sensitivity experiments for the runs with $\kappa=0.1,0.4$, and $1 \mathrm{~cm}^{2} \mathrm{~s}^{-1}$. For each of them, the zonal component $\tau_{x}$ of the wind stress was either reduced or increased in the latitude band between $5^{\circ}$ and $55^{\circ} \mathrm{N}$ according to the sinusoidal distribution: $\tau_{x}=\tau_{x 0}\left\{1+\left(c_{\tau}-1\right) \sin [\pi(y-5) / 50]\right\}$, where $y$ represents the latitude in degrees and $c_{\tau}$ the wind amplification factor successively set to $0.5,1$ (standard runs), and 1.5. The sinusoidal distribution avoids artificial divergence at the northern and southern limits of
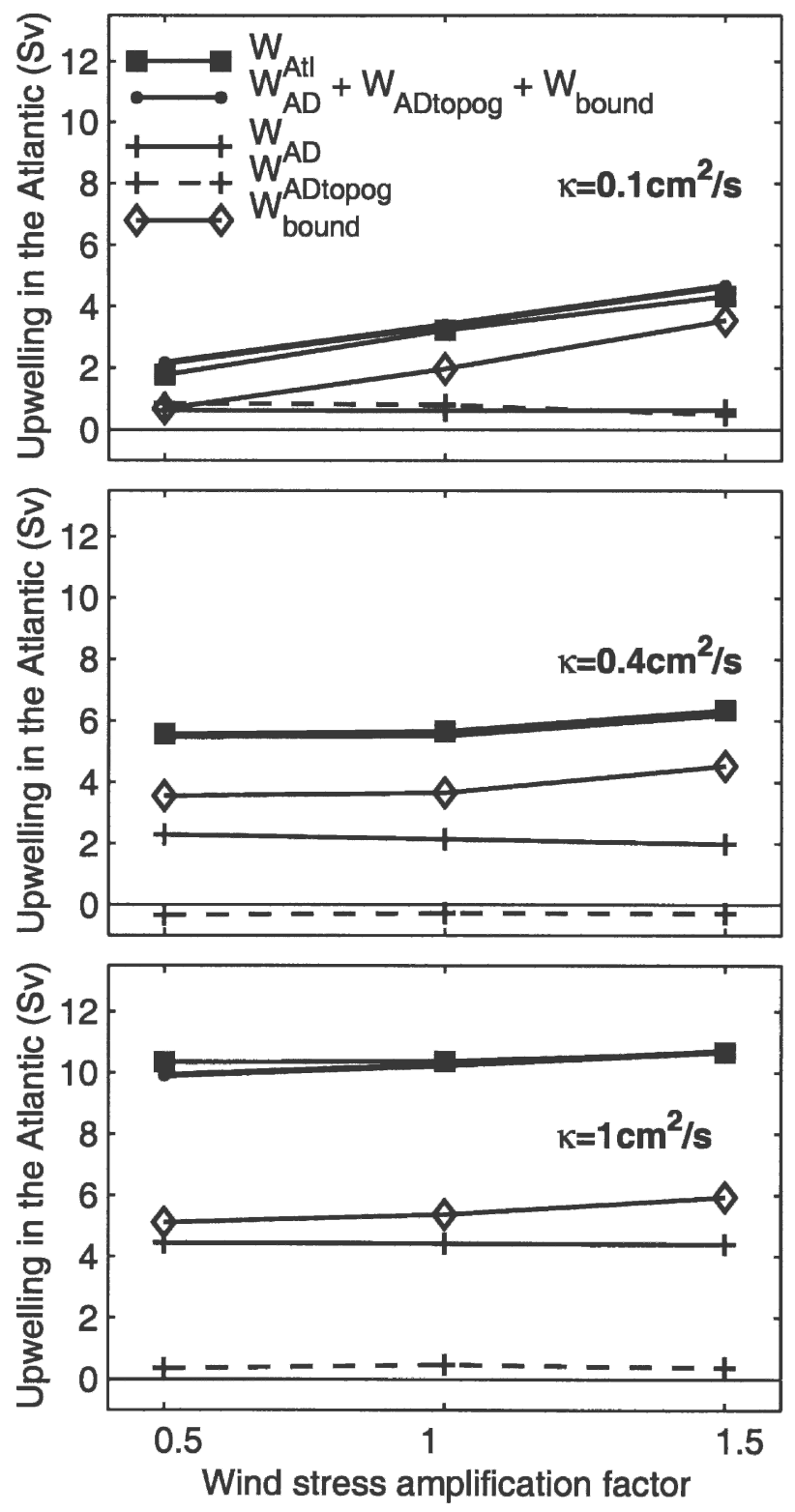

FIG. 12. Sensitivity of the Atlantic upwelling decomposition to the wind strength in the northern subtropics. Note that $W_{\mathrm{AD}}$ does not depend on the wind forcing, whereas $W_{\text {bound }}$ depends linearly on the wind amplification factor.

the modified area and is maximum in the region of the main boundary upwelling between $20^{\circ}$ and $40^{\circ} \mathrm{N}$. As seen in Fig. 12, both the Atlantic upwelling $W_{\text {Atl }}=$ $M_{\max }-M_{S}$ and the upwelling along boundaries $W_{\text {bound }}$ increase linearly with the wind amplification factor, while both components due to advection-diffusion balance are constant. This confirms that the residual upwelling along the boundaries is dependent on wind forcing. Although its sensitivity seems to decrease with $\kappa$, this result would be consistent with the suggestion of 
Yang (2003). Note that Rahmstorf (1995) also finds that the ageostrophic, frictional component dominates the boundary vertical flow in his coarse-resolution model.

Further analysis of the simulations reveals that the pycnocline depth is also very weakly sensitive to changes in the wind strength in the northern Atlantic subtropics (not shown). Following the discussion of section $4 \mathrm{~b}$, this suggests that winds in the Southern Ocean rather than in the low latitudes might have the dominant effect on the density structure in the Atlantic. This is consistent with Gnanadesikan (1999) and with several other studies proposing that Southern Ocean winds play a major role in controlling the Atlantic overturning magnitude (e.g., McDermott 1996; Klinger et al. 2003).

\section{Conclusions and discussion}

The sensitivity of the AMOC to vertical diffusivity was investigated in a global coupled model and used to decompose the strength of the Atlantic overturning $M_{\max }$ into simple components. The aim was to extract the main physical processes composing $M_{\max }$ in the coupled model and to discuss their sensitivity to $\kappa$. Note that we neglected the interaction between $\mathrm{AABW}$ and NADW although the coupling between the two, especially through topography-enhanced mixing, might potentially be important (Kamenkovich and Goodman 2000). The setup of the ocean component of the model allowed vertical diffusivities in the ocean interior as low as $\kappa=0.05 \mathrm{~cm}^{2} \mathrm{~s}^{-1}$, and this value was increased up to $\kappa=1.5 \mathrm{~cm}^{2} \mathrm{~s}^{-1}$ in a set of simulations. Our decomposition can be summarized as follows:

$$
\begin{aligned}
M_{\max } & =W_{\mathrm{Atl}}+M_{S} \text { with } \\
W_{\mathrm{Atl}} & =W_{\mathrm{AD}}+W_{\text {ADtopog }}+W_{\text {bound }} .
\end{aligned}
$$

The term $W_{\mathrm{AD}}$ represents the broad upwelling balancing the vertical diffusion in the Atlantic basin. It was computed by assuming a local one-dimensional balance between vertical advection and diffusion. Although its application is not trivial (see discussion by Munk and Wunsch 1998), a similar assumption was used by Munk (1966) to deduce one of the first global estimates of the amount of oceanic mixing and has been widely used since, especially by the geochemical community. Furthermore, it appears as the vertical balance in one class of solutions to the so-called thermocline equations (Stommel and Webster 1962) and it constitutes the starting point of several thermohaline theories (e.g., Bryan and Cox 1967; Bryan 1987; Gnanadesikan 1999). The resulting large-scale volume flux $W_{\mathrm{AD}}$ is to first approximation proportional to $\kappa$, and is responsible for the linear dependence of $W_{\text {Atl }}$ on $\kappa$. This linearity is in contradiction with the implicit assumptions of previous scaling arguments. Nevertheless, we showed that the latter could be reconciled with our model results by incorporating the linear increase of the density difference between high and low latitudes with $\kappa$. We argue that variations of the latter are particularly important here because of the coupling with the atmosphere as opposed to previous studies that used forced-ocean GCMs where the meridional density gradient was largely constrained by the surface-restoring conditions. On the other hand, the pycnocline depth is approximately constant in our experiments, while it is classically varying with the AMOC strength in forced simulations. The weak sensitivity of the pycnocline depth has already been reported by Levermann and Griesel (2004) in another set of experiments, and it is consistent with results from another coupled model of intermediate complexity (A. Gnanadesikan 2005, personal communication). Our results suggest that winds in the Southern Ocean primarily set the pycnocline depth and this issue should be further investigated in future studies.

The upwelling resulting from topographically enhanced mixing along the Atlantic coast is $W_{\text {ADtopog. }}$. This term can be positive or negative as a result of an increasing value of $\kappa$ with depth. Its order of magnitude is weaker than $1 \mathrm{~Sv}$. The upwelling term $W_{\text {bound }}$ is computed from the vertical velocity given by the model along the Atlantic coast only. It varies weakly with $\kappa$ and is strongest along the western boundary. We showed that $W_{\text {bound }}$ is linearly dependent on the wind stress in the North Atlantic, consistent with the study of Yang (2003).

The dominant term in Eq. (10), $W_{\mathrm{AD}}$, is computed merely from the tracer distribution, while $W_{\text {bound }}$ is derived from the velocity field at the boundary only. The fact that the sum of these two closes the budget of upwelling in the Atlantic basin allows us to interpret the two-dimensional $w_{\mathrm{AD}}$ field in Fig. 8 as a smoothed field of the upwelling velocities (computed through the continuity equation) in the ocean interior that has the same integral over the Atlantic excluding the boundary effect $W_{\text {bound }}$. This conclusion is of prime importance for the geochemical community who widely use it to infer dynamical statements on observed passive tracers and for observational estimates of mixing coefficients (e.g., A. C. Naveira Garabato 2005, personal communication).

The export of NADW at $30^{\circ} \mathrm{N}, M_{S}$, varies rather weakly with $\kappa$. It is strongly correlated with the strength of the overflow over the Greenland-Scotland ridge, 
and, thus, with the location of deep convection in the North Atlantic high latitudes, which was shown to be sensitive to $\kappa$ as well. It follows that $M_{\max }$ is sensitive to the characteristics of the water mass formed at a few grid points in the high latitudes, as was already shown in other modeling studies (e.g., Lenderik and Haarsma 1994; Rahmstorf 1995). However, in our model, this link is primarily felt by the amount of NADW exported at $30^{\circ} \mathrm{S}$, while processes in the Atlantic are not strongly influenced. This is consistent with results from Brix and Gerdes's (2003) global forced model, which also show a close relationship between enhanced southward export of NADW at $30^{\circ} \mathrm{S}$ and deep convection north of the Greenland-Scotland ridge.

The efficiency $R=M_{S} / M_{\max }$, on the other hand, was found to decrease linearly with $\kappa$ and to be largely independent of deep convection location. This could indicate that $M_{\max }$ is more strongly controlled by vertical mixing in the Atlantic than by that in the Indo-Pacific basin, although this issue was not investigated in detail here. It also showed that small values of $\kappa$-namely, $\kappa \leq 0.4 \mathrm{~cm}^{2} \mathrm{~s}^{-1}$-are required to obtain values of $R$ similar to those inferred from observations or from higher-resolution GCMs. Note that the sensitivity of this ratio $R$ is difficult to obtain in these computationally expensive models.

The variations of $M_{\max }$ with $\kappa$ result from the combined variations of all the terms of the decomposition. Our analysis suggests that, in general, scalings of $M_{\max }$ with $\kappa$ should take a constant offset into account, and that scalings such as those presented in Fig. 4 are not physical. This offset should be on the order of 10-11 Sv, where 8-9 Sv come from the southern outflow (Fig. 5) and $2 \mathrm{~Sv}$ from the offset of $W_{\text {Atl }}$ (Fig. 7). The approximately constant value of the Southern Ocean export is probably at least partly set by the winds in the Southern Ocean, as suggested, for example, by Rahmstorf and England (1997). The offset associated with $W_{\text {Atl }}$ is linked to the term $W_{\text {bound }}$ in our decomposition. Yet, its physical origin is more difficult to infer since the dynamics and circulation within the Atlantic might significantly change in the limit of zero vertical diffusivity. For comparison, the fit of $M_{\max }$ with an offset of $10.5 \mathrm{~Sv}$ yields an exponent of $\alpha=0.57$ in the standard runs (Fig. 13) and $\alpha=0.73$ in the runs using $\kappa^{\text {lowlat }}$ (not shown). These exponents result, however, from the combination of different components with different sensitivities to $\kappa$. The validity of scaling laws in general is indeed related to unchanged physical processes. Because of the switch in deep convection location, this condition is not fulfilled in both sets of experiments. In the range of background diffusivity values where no

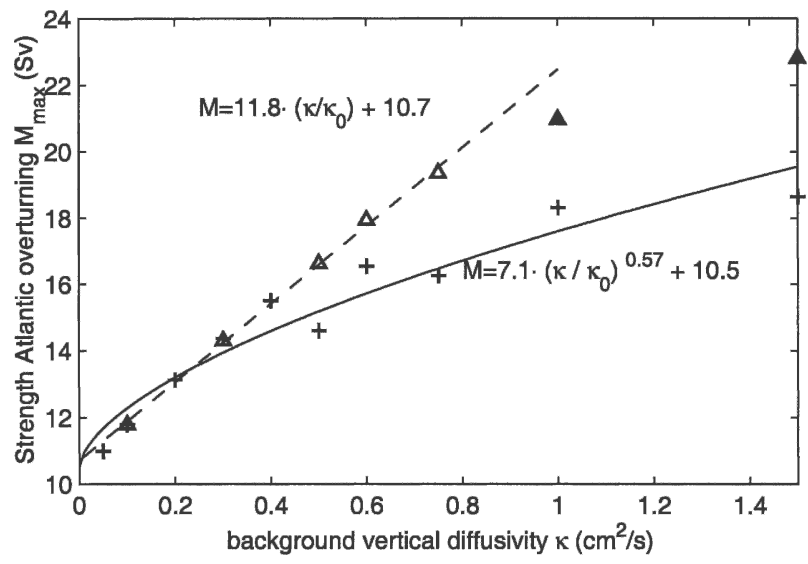

FIG. 13. Maximum Atlantic overturning against background vertical diffusivity in the standard configuration (crosses) and for the runs using $\kappa=0.1 \mathrm{~cm}^{2} \mathrm{~s}^{-1}$ in the high latitudes (triangles). The dashed line shows the linear fit for values of $\kappa^{\text {lowlat }}<1 \mathrm{~cm}^{2} \mathrm{~s}^{-1}$ (open triangles). The continuous line shows the least squares fit by a power law with a constant offset of $11 \mathrm{~Sv}$ for the standard runs $\left(\kappa_{0}=1 \mathrm{~cm}^{2} \mathrm{~s}^{-1}\right)$.

switch in deep convection sites is detected, that is for $\kappa^{\text {lowlat }}<1 \mathrm{~cm}^{2} \mathrm{~s}^{-1}, M_{\max }$ scales linearly with $\kappa^{\text {lowlat }}$ (Fig. 13, dashed line), in agreement with the decomposition. The offset value of $10.7 \mathrm{~Sv}$ is very close to our prediction. To conclude, we first recall that scaling laws should, in general, be derived from dynamics and physical laws and not be simply fitted. Furthermore, we suggest that scaling laws be interpreted with much care not only because of the generally very small range of $\kappa$ (that is physically justified) but also because of shifts in important physical processes such as deep convection location.

Acknowledgments. The authors acknowledge the efforts and achievements of Marisa Montoya, Matthias Hofmann, and Miguel Morales Maqueda in developing the model.

They are also grateful to Andrey Ganopolski and Stefan Rahmstorf for useful discussions and to Anand Gnanadesikan and an anonymous reviewer for constructive comments that helped us to greatly clarify the results. Also, JM thanks Jerome Sirven for stimulating discussions. Both JM and AL were supported by the Gary Comer foundation, and AG was funded through the James S. McDonnell Foundation Centennial Fellowship.

\section{REFERENCES}

Boccaletti, G., R. C. Pacanowski, S. G. H. Philander, and A. Fedorov, 2004: The thermal structure of the upper ocean. $J$. Phys. Oceanogr., 34, 888-902. 
— R. Ferrari, A. Adcroft, and J. Marshall, 2005: The vertical structure of ocean heat transport. Geophys. Res. Lett., 32, L10603, doi:10.1029/2005GL022474.

Böning, C. W., W. R. Holland, F. O. Bryan, G. Danabasoglu, and J. C. McWilliams, 1995: An overlooked problem in model simulations of the thermohaline circulation and heat transport in the Atlantic Ocean. J. Climate, 8, 515-523.

Brix, H., and R. Gerdes, 2003: North Atlantic Deep Water and Antarctic Bottom Water: Their interaction and influence on the variability of the global ocean circulation. J. Geophys. Res., 108, 3022, doi:10.1029/2002JC001335.

Bryan, F., 1987: Parameter sensitivity of primitive equation ocean general circulation models. J. Phys. Oceanogr., 17, 970-985.

Bryan, K., and M. D. Cox, 1967: A numerical investigation of the oceanic general circulation. Tellus, 19, 54-80.

Clarke, P. U., N. G. Pisias, T. F. Stocker, and A. J. Weaver, 2002: The role of the thermohaline circulation in abrupt climate change. Nature, 415, 863-869.

Colin de Verdière, A., 1988: Buoyancy driven planetary flows. $J$. Mar. Res., 46, 215-265.

Delworth, T. L., S. Manabe, and R. J. Stouffer, 1993: Interdecadal variations of the thermohaline circulation in a coupled ocean-atmosphere model. J. Climate, 6, 1993-2011.

— , and Coauthors, 2006: GFDL's CM2 global coupled climate models. Part I: Formulation and simulation characteristics. $J$. Climate, 19, 643-674.

Dickson, R., and J. Brown, 1994: The production of North Atlantic Deep Water: Sources, rates and pathways. J. Geophys. Res., 99, 12 319-12 341.

Fichefet, T., and M. A. M. Maqueda, 1997: Sensitivity of a global sea ice model to the treatment of ice thermodynamics and dynamics. J. Geophys. Res., 102, 12 609-12 646.

Furevik, T., M. Bentsen, H. Drange, I. K. T. Kindem, N. G. Kvamst $\varnothing$, and A. Sorteberg, 2003: Description and evaluation of the Bergen Climate Model: ARPEGE coupled with MICOM. Climate Dyn., 21, 25-51.

Ganachaud, A., and C. Wunsch, 2000: Improved estimates of global ocean circulation, heat transport and mixing from hydrographic data. Nature, 408, 453-456.

Ganopolski, A., S. Rahmstorf, V. Petoukhov, and M. Claussen, 1998: Simulation of modern and glacial climates with a coupled global model of intermediate complexity. Nature, 391, 351-356.

Gent, P. R., and J. C. McWilliams, 1990: Isopycnal mixing in ocean circulation models. J. Phys. Oceanogr., 20, 150-155.

Gnanadesikan, A., 1999: A simple predictive model for the structure of the oceanic pycnocline. Science, 283, 2077-2079.

— R. D. Slater, P. S. Swathi, and G. K. Vallis, 2005: The energetics of ocean heat transport. J. Climate, 18, 2604-2616.

Gregg, M. C., 1989: Scaling turbulent dissipation in the thermocline. J. Geophys. Res., 94, 9686-9698.

Griesel, A., and M. A. M. Maqueda, 2006: The relation of meridional pressure gradients to North Atlantic Deep Water volume transport in an ocean general circulation model. Climate Dyn., in press.

Griffies, S. M., 1998: The Gent-McWilliams skew flux. J. Phys. Oceanogr., 28, 831-841.

Hasumi, H., and N. Suginohara, 1999: Effects of locally enhanced vertical diffusivity over rough bathymetry on the World Ocean circulation. J. Geophys. Res., 104, 23 364-23 374.

Hofmann, M., and M. A. M. Maqueda, 2006: Performance of a second-order moments advection scheme in an ocean general circulation model. J. Geophys. Res., in press.
Hu, D., 1996: On the sensitivity of thermocline depth and meridional heat transport to vertical diffusivity in OGCMs. J. Phys. Oceanogr., 26, 1480-1494.

Huang, R. X., 1999: Mixing and energetics of the oceanic thermohaline circulation. J. Phys. Oceanogr., 29, 727-746.

Huck, T., A. J. Weaver, and A. Colin de Verdière, 1999: On the influence of the parameterization of lateral boundary layers on the thermohaline circulation in coarse-resolution ocean models. J. Mar. Res., 57, 387-426.

Kalnay, E., and Coauthors, 1996: The NCEP/NCAR 40-Year Reanalysis Project. Bull. Amer. Meteor. Soc., 77, 437-471.

Kamenkovich, I., and P. Goodman, 2000: The dependence of AABW transport in the Atlantic on vertical diffusivity. Geophys. Res. Lett., 27, 3739-3742.

Klinger, B. A., S. Drijfhout, J. Marotzke, and J. R. Scott, 2003: Sensitivity of basinwide meridional overturning to diapycnal diffusion and remote wind forcing in an idealized AtlanticSouthern Ocean geometry. J. Phys. Oceanogr., 33, 249-266.

Large, W. G., J. C. McWilliams, and J. C. Doney, 1994: Oceanic vertical mixing: A review and a model with a nonlocal boundary layer parameterization. Rev. Geophys., 32, 363-403.

Latif, M., E. Roeckner, U. Mikolajewicz, and R. Voss, 2000: Tropical stabilization of the thermohaline circulation in a greenhouse warming simulation. J. Climate, 13, 1809-1813.

Ledwell, J. R., A. J. Watson, and C. S. Law, 1993: Evidence for slow mixing across the pycnocline from an open-ocean tracerrelease experiment. Nature, 364, 701-703.

— , E. T. Montgomery, K. L. Polzin, L. C. St. Laurent, R. W. Schmitt, and J. M. Toole, 2000: Evidence for enhanced mixing over rough topography in the abyssal ocean. Nature, 403, 179-182.

Lenderik, G., and R. J. Haarsma, 1994: Variability and multiple equilibria of the thermohaline circulation associated with deep-water formation. J. Phys. Oceanogr., 24, 1480-1493.

Levermann, A., and A. Griesel, 2004: Solution of a model for the oceanic pycnocline depth: Scaling of overturning strength and meridional pressure difference. Geophys. Res. Lett., 31, L17302, doi:10.1029/2004GL020678.

Levitus, S., 1982: Climatological Atlas of the World Ocean. NOAA Prof. Paper 13, 173 pp. and 17 microfiche.

Luyten, J. R., J. Pedlosky, and H. Stommel, 1983: The ventilated thermocline. J. Phys. Oceanogr., 13, 292-309.

Manabe, S., and R. J. Stouffer, 1999: The role of thermohaline circulation in climate. Tellus, 51AB, 91-109.

Marotzke, J., 1997: Boundary mixing and the dynamics of threedimensional thermohaline circulations. J. Phys. Oceanogr., 27, 1713-1728.

— , and F. Scott, 1999: Convective mixing and the thermohaline circulation. J. Phys. Oceanogr., 29, 2962-2970.

McDermott, D. A., 1996: The regulation of northern overturning by Southern Hemisphere winds. J. Phys. Oceanogr., 26, 12341255.

McManus, J. F., R. Francois, J.-M. Gherardi, L. D. Keigwin, and S. Brown-Leger, 2004: Collapse and rapid resumption of Atlantic meridional circulation linked to deglacial climate changes. Nature, 428, 834-837.

Montoya, M., A. Griesel, A. Levermann, J. Mignot, M. Hofmann, A. Ganopolski, and S. Rahmstorf, 2005: The Earth system model of intermediate complexity CLIMBER-3 $\alpha$. Part I: Description and performance for present day conditions. Climate Dyn., 25, 237-263.

Munk, W. H., 1950: On the wind-driven ocean circulation. J. Meteor., 7, 79-93. 
1966: Abyssal recipes. Deep-Sea Res., 13A, 707-730.

and C. Wunsch, 1998: Abyssal recipes II: energetics of tidal and wind mixing. Deep-Sea Res., 45A, 1977-2010.

Park, Y.-G., 1999: The stability of the thermocline circulation in a two-box model. J. Phys. Oceanogr., 29, 3101-3110.

— , and K. Bryan, 2000: Comparison of thermally driven circulations from a depth-coordinate model and an isopycnal layer model. Part I: Scaling-law sensitivity to vertical diffusivity. $J$. Phys. Oceanogr., 30, 590-605.

Petoukhov, V., A. Ganopolski, V. Brovkin, M. Claussen, A. Eliseev, C. Kubatzki, and S. Rahmstorf, 2000: CLIMBER 2: A climate system model of intermediate complexity. Part I: Model description and performance for present climate. Climate Dyn., 16, 1-17.

Prange, M., G. Lohmann, and A. Paul, 2003: Influence of vertical mixing on the thermohaline hysteresis: Analysis of an OGCM. J. Phys. Oceanogr., 33, 1707-1721.

Prather, M. J., 1986: Numerical advection by conservation of second-order moments. J. Geophys. Res., 91, 6671-6681.

Rahmstorf, S., 1995: Multiple convection patterns and thermohaline flow in an idealized OGCM. J. Climate, 8, 3028-3039.

- 2002: Ocean circulation and climate during the past 120,000 years. Nature, 419, 207-214.

_ , and M. H. England, 1997: Influence of Southern Hemisphere winds on North Atlantic deep water flow. J. Phys. Oceanogr., 27, 2040-2054.

Saenko, O. A., and W. J. Merryfield, 2005: On the effect of topographically enhanced mixing on the global ocean circulation. J. Phys. Oceanogr., 35, 826-834.

Stommel, H. M., and J. Webster, 1962: Some properties of the thermocline equations in the subtropical gyres. J. Mar. Res., 20, 42-56.
Talley, L. D., J. L. Reid, and P. E. Robbins, 2003: Data-based meridional overturning streamfunctions for the global oceans. J. Climate, 16, 3213-3226.

Timmermann, A., M. Latif, R. Voss, and A. Grötzner, 1998: North Atlantic interdecadal variability: A coupled air-sea mode. $J$. Climate, 11, 1906-1932.

Toggweiler, J. R., and B. Samuels, 1993: Is the magnitude of the deep outflow from the Atlantic Ocean actually governed by Southern Hemisphere winds? The Global Carbon Cycle, M. Heimann, Ed., NATO ASI Series, Vol. I 15, Springer-Verlag, 303-331.

— and - 1995: Effect of Drake Passage on the global thermohaline circulation. Deep-Sea Res., 42A, 477-500.

$\longrightarrow$, and - 1998: On the ocean's large-scale circulation near the limit of no vertical mixing. J. Phys. Oceanogr., 28, 1832 1852.

Toole, J. M., K. L. Polzin, and R. W. Schmitt, 1994: Estimates of diapycnal mixing in the abyssal ocean. Science, 264, 11201123.

Vellinga, M., and P. Wu, 2004: Low-latitude freshwater influence on centennial variability of the Atlantic thermohaline circulation. J. Climate, 17, 4498-4511.

Veronis, G., 1975: The role of models in tracer studies. Numerical Models of Ocean Circulation, National Academy of Science, 133-146.

Yang, J., 2003: On the importance of resolving the western boundary layer in wind-driven ocean general circulation models. Ocean Modell., 5, 357-379.

Zhang, J., R. W. Schmitt, and R. X. Huang, 1999: The relative influence of diapycnal mixing and hydrologic forcing on the stability of the thermohaline circulation. J. Phys. Oceanogr., 29, 1096-1108. 